Scientific Review - Engineering and Environmental Sciences (2021), 30 (1), 16-28

Sci. Rev. Eng. Env. Sci. (2021), 30 (1)

Przegląd Naukowy - Inżynieria i Kształtowanie Środowiska (2021), 30 (1), 16-28

Prz. Nauk. Inż. Kszt. Środ. (2021), 30 (1)

http://iks.pn.sggw.pl

DOI 10.22630/PNIKS.2021.30.1.2

Labeeb S. Al-YASSRI, Munaf A. Al-RAMAHEE, Alaa M. Al-KHEKANI

University of Al-Qadisiyah, College of Engineering

\title{
Experimental investigations on concrete beams reinforced with equivalent service steel pipe
}

Key words: duct, flexural, opening, steel pipe, reinforced concrete beams

\section{Introduction}

With modern construction, the passage of utility connections (electricity, communication, etc.) through structural members has become a common technique. The process of transferring service tubes through the structural elements is done by making holes in the body of the structural element. Numerous researches have been carried out to investigate these openings effects and the factors affecting them on the behavior of structural elements. The openings can be categorized according to their shape (rectangular, circular, etc.), their size (small or large), their location within the element, and their direction (transverse or longitudinal). Different studies have considered these properties experimentally (Prentzas, 1968; Somes \& Corley, 1974; Mansur, Tan \& Lee, 1984; Ha- snat \& Akhtanizzaman, 1987; Herrera, Anacleto-Lupianez \& Lemnitzer, 2017; Al-Khekany, Al-Yassri \& Abbas, 2018; Al-Yasri, Al-Khekany \& Abbas, 2018; Makki, Jassem \& Jassem, 2018).

Ashour and Rishi (2000) investigated the effect of web reinforcement, size, and position of the rectangular opening using 16 two-span continuous deep beams. Two positions of rectangular openings were considered, with outer and inner shear span.

The opening location controlled mainly the failure mode where the maximum decrease in the load capacity occurred when the opening was in the interior shear span. Yang, Eun and Chung (2006) investigated the effect of the rectangular opening with different sizes on the performance of reinforced concrete (RC) deep beams. Different concrete compressive strength was considered in the study. Different shear span-to-depth (a/d) ratios were considered in this study. The effect of vertical web reinforcement was found to have more impact 
on the load-carrying capacity of deep beam than the horizontal reinforcement. Amin, Agarwal and Aziz (2013) studied the opening properties on the shear strength behavior of deep beams with the lack of web reinforcement. Their results showed that the location of openings has a significant effect when openings are located at shear zone where the ultimate shear strength was significantly decreased. However, the opening located at mid-span of the beam had a slight effect where the shear strength increased with the decrease of the openings size. Campione and Minafò (2012) investigated the behavior of $\mathrm{RC}$ deep beams with different positions of openings and low shear span-to-depth ratio. The experimental results showed that the position of the opening along the beam length affected the structural behavior of the deep beam.

The presence of openings in different building structural members is important in some cases, but most of codes of practice (Canadian Standard Association [CSA], 2004; Arya, 2009; American Concrete Institute [ACI], 2014) do not suggest any procedure for the design of such type of members. Most investigational experiments in the literature conducted experimental researches on beams with the transverse opening only.

Few studies considered the effect of the longitudinal openings on the structural behavior where beams with an opening along the longitudinal axis has a constant section. Since these openings are considered a weak property, the plane of failure usually goes within these openings. Therefore, in this study, a test of RC beams with steel pipe as main reinforcement as an equivalent to the traditional reinforcement and have a constant cross-section along the beam was presented. The equivalency of reinforcement based on the moment equivalent under the service load between the two types of reinforcing from beam section analysis. Therefore, the reinforcing pipes were employed also as ducts to allow all services to pass through the beam without any need to cover the utilities by a suspended ceiling. Moreover, the overall weight of building can be reduced by adopting a large steel pipe as a main reinforcement especially for a multistory building.

\section{Design and experimental work}

Four beams were prepared. Two of them were manufactured with traditional reinforcement while the other two beams were manufactures with equivalent circular pipes. The pipes geometries were selected based on the equivalent sectional moment. From the sectional analysis, the nominal moment at tensile reinforcement was calculated first for the traditional reinforcement based on section equilibrium, and then the resulted moment was used for the designing of the steel pipe reinforced beams. The cross section of all tested beams were 200X and $250 \mathrm{~mm}(b, h)$ and overall length $(L)$ was $1,500 \mathrm{~mm}$. The selection of reinforcing bars was based on the target of the failure mode which is set to be a flexural tensile failure. The first traditional reinforced beam TRB1 was reinforced with 3 $\varnothing 12 \mathrm{~mm}$ as the main reinforcement. The second traditional reinforced beam TRB2 was mainly reinforced with $2 ø 12 \mathrm{~mm}$ and $1 ø 16 \mathrm{~mm}$. The first pipe reinforced 
beam PRB1 was reinforced with $2 ø 50$ $\mathrm{mm}$ as the main reinforcement while it was reinforced with $1 \varnothing 75 \mathrm{~mm}$ for the second pipe reinforced beams (PRB2). The thickness of all pipes was $3 \mathrm{~mm}$. All four beams were reinforced with $ø 10$ mm@150 mm c/c for the shear reinforcement. All beams were reinforced with $ø 12 \mathrm{~mm}$ top reinforcement for practical consideration. Table 1, Figures 1 and 2 show the tested beam details. To prevent the bond failure of the steel pipes, the smooth surface of the pipes was welded with around the outer diameter and along the beam to create a coarse surface to work as mechanical ribs and ensure the interaction between and concrete and pipes as shown in Figure 3.
All beams were cast using a proportion of $1: 1.5: 3$ (cement: sand:aggregate). Locally produced commercial Portland cement (PC) type I the follows the the standard IQS 5/1984 requirements (Central Organization for Standardization and Quality Control [COSQC], 1984a). The fine and the coarse aggregate were selected to satisfy the standard IQS 45/1984 (COSQC 1984b). The $19 \mathrm{~mm}$ size rounded gravel were used as coarse aggregate with 2.64 specific gravity. Natural sand of 2.60 specific gravity was used. The mechanical properties of reinforcing bars used in this research are listed in Table 2. The beams were cast using pre-cleaned ply-wood molds as shown in Figure 4. Finally, after demolding, the samples were painted

TABLE 1. Beam reinforcement details

\begin{tabular}{|l|c|c|c|c|}
\hline $\begin{array}{l}\text { Beam } \\
\text { symbol }\end{array}$ & $\begin{array}{c}\text { Opening size } \\
{[\mathrm{mm}]}\end{array}$ & Longitudinal bar & Transverse bar & Equivalent beam \\
\hline TRB1 & - & $3 \varnothing 12$ & $\varnothing 10 @ 150 \mathrm{~mm}$ & - \\
\hline TRB2 & - & $2 ø 12+1 \varnothing 16$ & $\varnothing 10 @ 150 \mathrm{~mm}$ & - \\
\hline PRB1 & $2 \varnothing 50$ & $2 ø 50$ steel pipe & $\varnothing 10 @ 150 \mathrm{~mm}$ & TRB1 \\
\hline PRB2 & $1 \varnothing 75$ & $1 ø 75$ steel pipe & $\varnothing 10 @ 150 \mathrm{~mm}$ & TRB2 \\
\hline
\end{tabular}
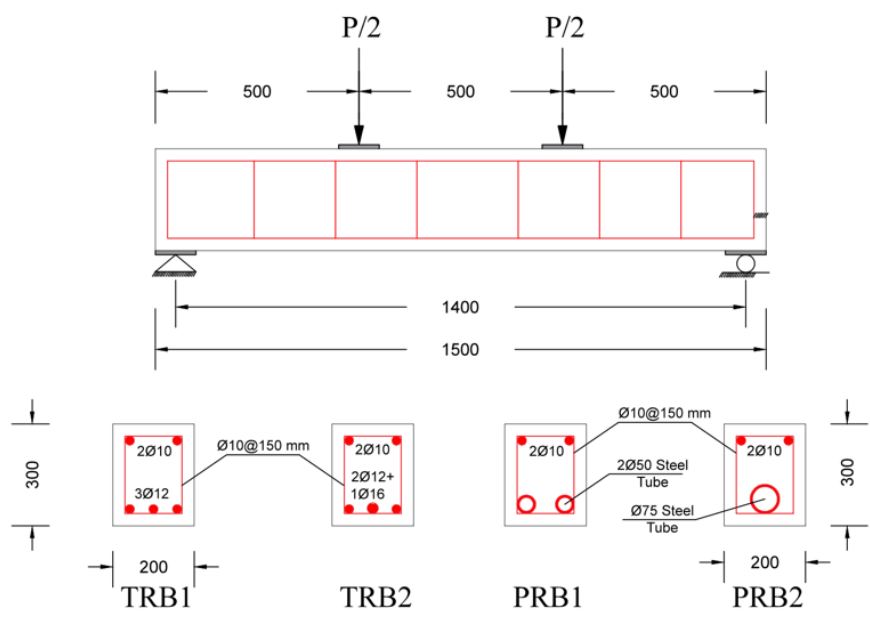

All dimension are in $\mathrm{mm}$

FIGURE 1. Details of tested beams 


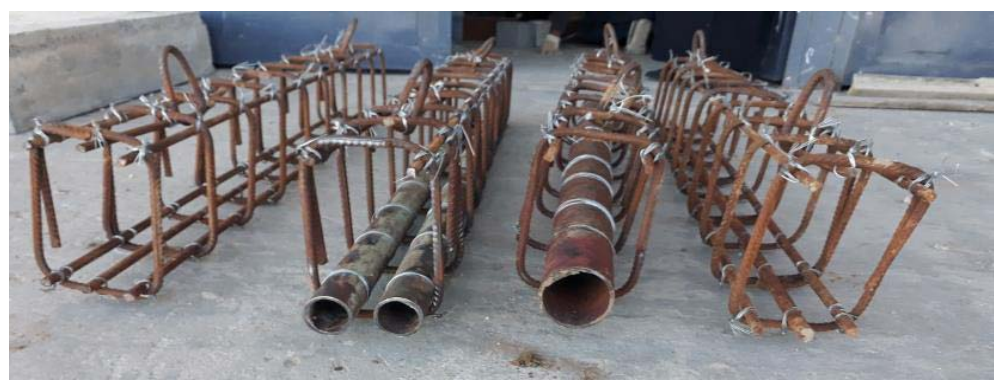

FIGURE 2. Reinforcement arrangement of the tested beams



FIGURE 3. Welded points along the pipe

TABLE 2. Reinforcement properties

\begin{tabular}{|l|c|c|c|}
\hline Reinforcement type & $\begin{array}{c}\text { Diameter } \\
{[\mathrm{mm}]}\end{array}$ & $\begin{array}{c}\text { Yield strength } \\
{[\mathrm{MPa}]}\end{array}$ & $\begin{array}{c}\text { Ultimate strength } \\
{[\mathrm{MPa}]}\end{array}$ \\
\hline$\varnothing 12 \mathrm{~mm}$ steel bar & 11.93 & 423 & 637 \\
\hline$\varnothing 16 \mathrm{~mm}$ steel bar & 15.88 & 450 & 666 \\
\hline$\varnothing 50 \mathrm{~mm}$ steel pipe & 50.00 & 268 & 396 \\
\hline$\varnothing 75 \mathrm{~mm}$ steel pipe & 75.00 & 268 & 396 \\
\hline
\end{tabular}

prior to the test to easily recognize the formulation of cracks during different loading stages along the beam. The average 28-day concrete compressive strengths was $30.6 \mathrm{MPa}$ based on $150 \times 150 \times 150$ cubes.

All beams were loaded monotonically until failure using a universal testing machine with a capacity of $1,000 \mathrm{kN}$ as shown in Figure 5. All beams were tested using a four-point load configuration under loading control. The preparation, curing, and test were conducted at the Concrete Lab of Civil Engineering Department in Al-Qadisiyah University. The mid-span displacement was recorded using an LVDT connected to a data logger system with a sampling frequency of $2 \mathrm{~Hz}$. 


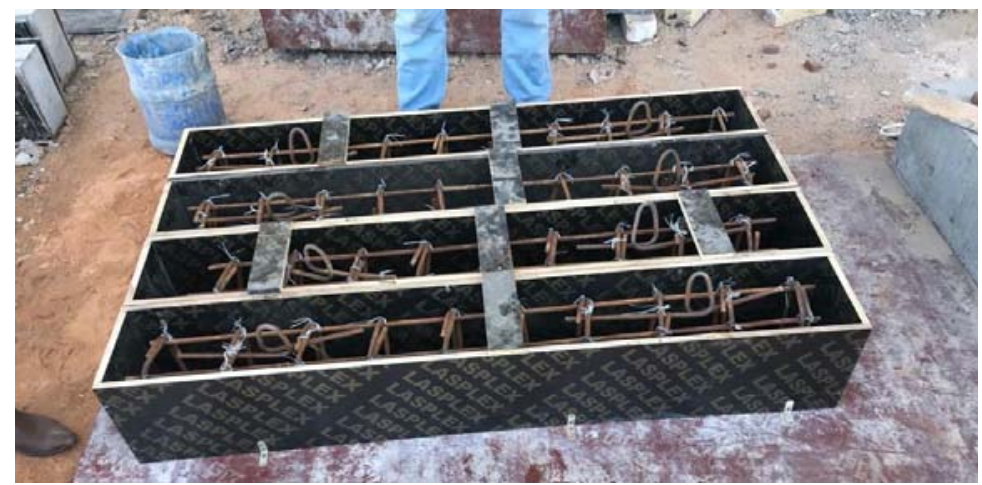

FIGURE 4. Samples preparation

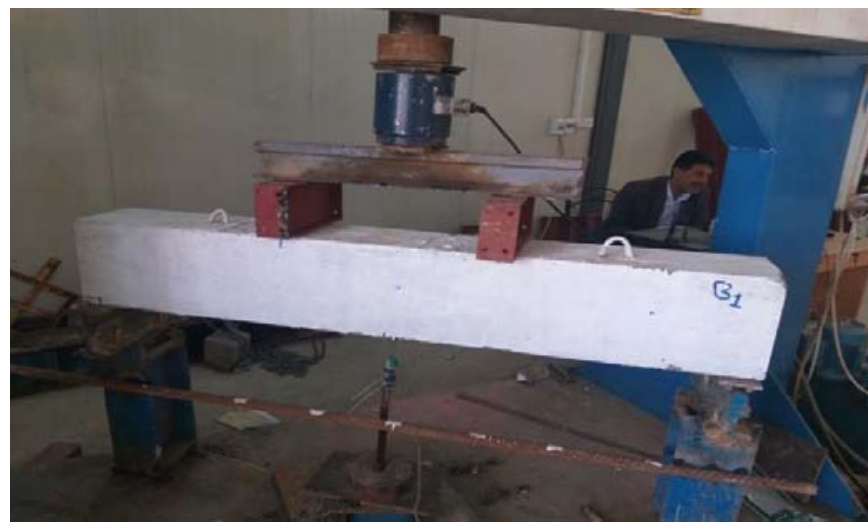

FIGURE 5. Test set up

\section{Results and discussion}

From a typical load-deflection relationship, usually, three stages can be observed. In the first stage which is known as cracking stage, as the specimens are loaded monotonically, a linear increase in the vertical displacement is recorded. After that, there is a curvature in a load-displacement curve up to failure where the slope of the load-deflection curve will be decreased significantly with a large increment in displacement and a small increase in the applied loading up to failure. The flexural cracks were de- tected initially in middle region between the applied loads. These flexural cracks were speared along the shear span as the load increased.

The mode of failure of all tested beams was a flexural tension except for PRB2 where the failure mode was anchorage failure at the left support. Final failure was occurred by the opening and widening of flexural cracks due to reaching the ultimate tensile strain by the main reinforcement. Horizontal cracks appeared first on the tension reinforcement level and then expanded to the beam end with loading increase. This failure mode 
has specified a diagonal tension crack which is described as a main crack ranging from bottom main reinforcement to the loading point (Sethunarayanan, 1960). Table 3 summarizes the results in terms of load and deflection at cracking and ultimate stages. and widen with a loss in the beam stiffness. The dominant failure mode as mentioned was the yielding of tension reinforcing steel, following by the concrete crushing under points load at the ultimate load about $192 \mathrm{kN}$. The load-displacement relationship for TRB1 and

TABLE 3. Summary of results

\begin{tabular}{|l|c|c|c|c|}
\hline \multirow{2}{*}{ Beam } & \multicolumn{2}{|c|}{ Load $[\mathrm{kN}]$} & \multirow{2}{*}{$\begin{array}{c}\text { Deflection } \\
{[\mathrm{mm}]}\end{array}$} & Mode of failure \\
\cline { 2 - 3 } & cracking & ultimate & 8.49 & flexural tensile \\
\hline TRB1 & 30 & 192 & 8.50 & flexural tensile \\
\hline TRB2 & 30 & 204 & 8.30 & flexural tensile \\
\hline PRB1 & 25 & 161 & 8.01 & end anchorage \\
\hline PRB2 & 22 & 184 & &
\end{tabular}

The first visible crack for TRB1 was recorded in the zero-shear area at a load level of $30 \mathrm{kN}$. With loading increase, additional flexural cracks initiated, and diagonal shear cracks appeared close to the supports. At the load level of $165 \mathrm{kN}$, the cracks between loading points at the tension face of the beam began to widen. After that, cracks continued to develop crack pattern at ultimate load are shown in Figures 6 and 7, respectively.

Beam PRB1 was fabricated as an equivalent for TRB1 based on the moment from the sectional analysis. As mentioned earlier, it was reinforced with a $2 \varnothing 50 \mathrm{~mm}$ steel pipe as the main reinforcement. The visible crack was recorded as a load level of $25 \mathrm{kN}$. It can be

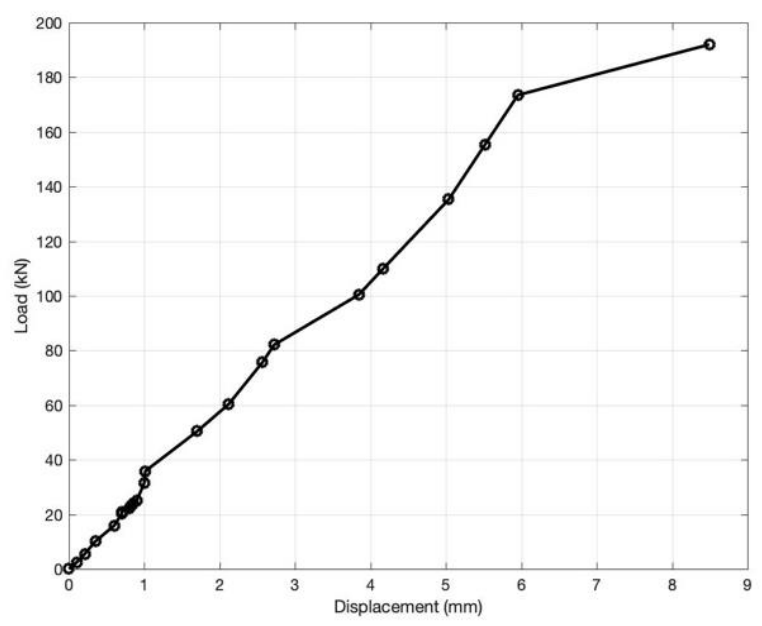

FIGURE 6. Load-displacement for TRB1 




FIGURE 7. Crack pattern at ultimate load for TRB1

observed there is a reduction in cracking load of about $5 \mathrm{kN}$ comparing to TRB1. The reason behind this reduction is due to the decrease in uncracked moment of inertia (gross moment of inertia) due to the presence of opening. More flexural and diagonal shear cracks began to initiate with the increasing of a load on the tension face throughout the beam. As the load increased, a major crack widened and propagated to the compression top fiber and flexural tensile failure occurred at a load level of about $161 \mathrm{kN}$. Figures
8 and 9 show the load-displacement relationship and crack pattern at the ultimate load for PRB1, respectively. Figure 10 shows the comparison between TRB1 and PRB1. As shown from Figure 10, it can be noticed, there is a decrease in the ultimate load of PRB1 compared to TRB1 about $16 \%$ due to the smoothness of the pipe that led to the decrease in the strength of the beam. Also, it can be observed from Figure 10 that the after cracking stiffness of PRB1 larger than the reference TRB1 this behavior can

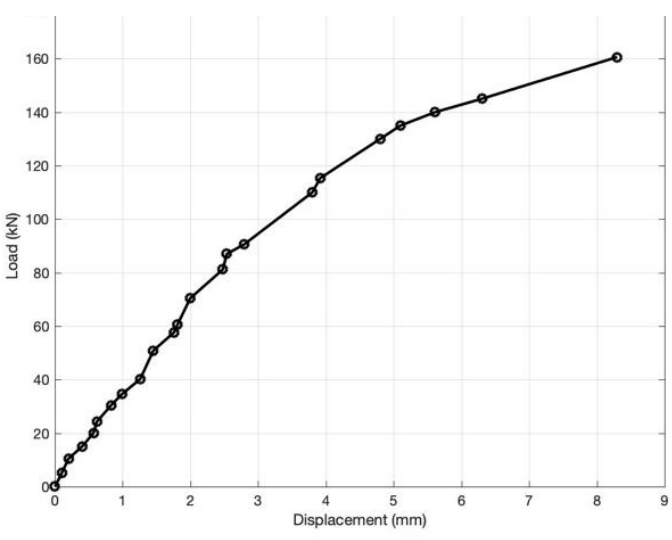

FIGURE 8. Load-displacement for PRB1 


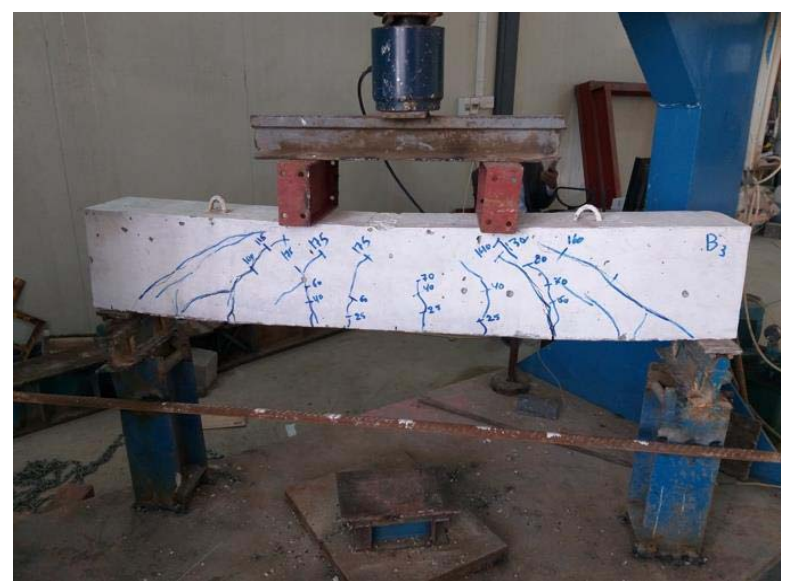

FIGURE 9. Crack pattern at ultimate load for PRB1



FIGURE 10. Comparison of TRB1 and PRB1

be attributed to the increase in stiffness of steel pipes with respect to traditional steel bars as well as the bond strength along the steel pipes is larger than the bond strength along the traditional steel rebars due to the surface area.

The first visible crack for the second traditional reinforced beam TRB2 was also recorded between the two-point load at a load level of $30 \mathrm{kN}$. In the same manner to TRB1, more flexural cracks initiated with the increase of the applied load. At the load level of $80 \mathrm{kN}$, the diagonal shear cracks started to appear in the shear span. After that, cracks continued to develop and widen with a loss in the beam stiffness. The load-displacement relationship for TRB2 is shown in 


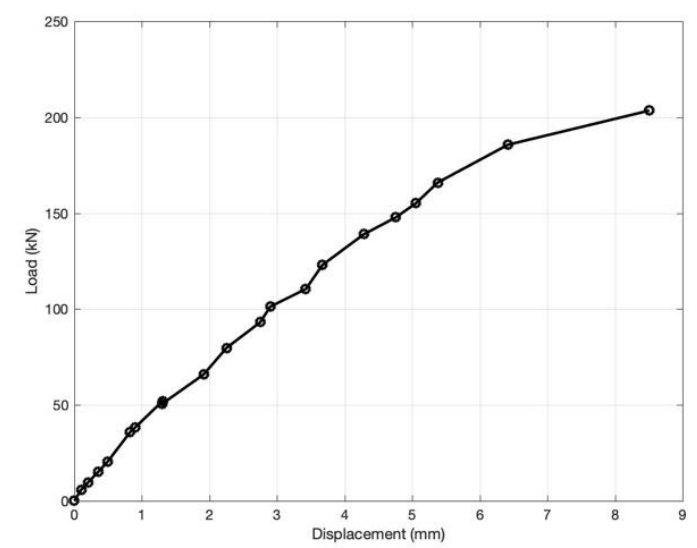

FIGURE 11. Load-displacement for TRB2

Figure 11. The failure mode for this beam was the flexural tensile failure followed by the crushing of concrete in extreme compression fiber at a load level of $203 \mathrm{kN}$ as shown in Figure 12. the fact that the beam with an open section has a lower gross moment of inertia and an effective moment of inertia that led to a decrease in the strength of the beam. At the load level of 184, an anchorage



FIGURE 12. Crack pattern at ultimate load for TRB2

Beam PRB2 which is equivalent to TRB2 based on the same concept above was reinforced with $1 \varnothing 75 \mathrm{~mm}$ steel pipe as the main reinforcement. The visible crack was recorded as a load level of $22 \mathrm{kN}$ which is less by $25 \%$ compared to TRB2. This difference is related also to failure occurred in the right support of the beam led to a beam failure. This failure is due to the large size of the opening with respect to the section's width that provided insufficient surrounding concrete around the steel pipe. Figures 13 and 14 show the load-displacement rela- 


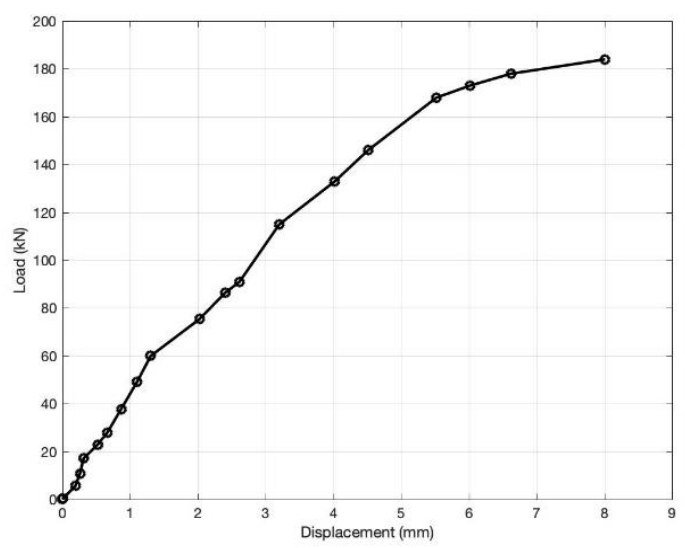

FIGURE 13. Load-displacement for PRB2

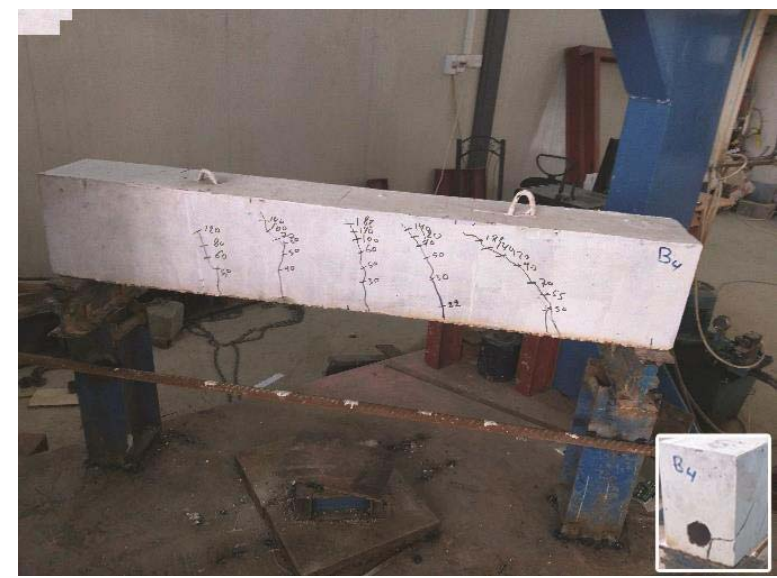

FIGURE 14. Crack pattern at ultimate load for PRB2

tionship and crack pattern at the ultimate load for PRB2, respectively.

As shown from Figure 15, which represents the comparison between TRB2 and PRB2, a good agreement in the behavior of the two beams prior to the failure of PRB2. The difference in the ultimate load was about $10 \%$ which is due to anchorage failure in PRB2. It can be observed from Figure 15, that after cracking, the stiffness of PRB2 larger than the reference TRB2. This behavior can be attributed to the larger stiffness of steel pipes with respect to the traditional reinforcement as well as the bond strength along the steel pipes is larger than the bond strength along the traditional steel rebars which have a smaller surface area.

\section{Conclusions}

Based on the results and observations of current study that implemented for the tested RC beam, the following conclusions can be drawn: 


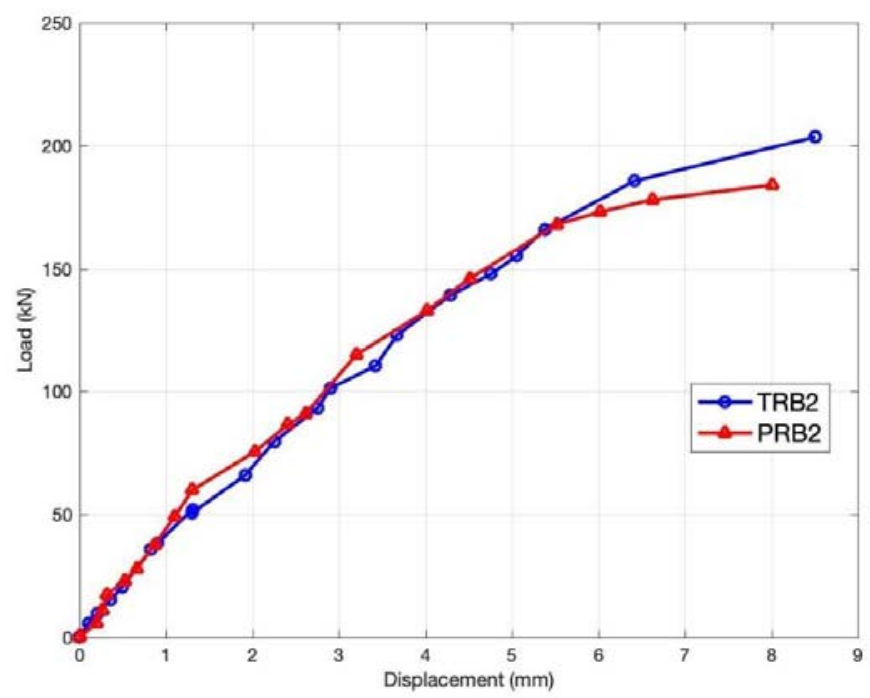

FIGURE 15. Comparison of TRB2 and PRB2

- Replacement of traditional rebars by an equivalent steel pipe with respect to flexural capacity shows a promising result of ductility, cracking pattern, ultimate strength and mode of failure compared to the reference beam with traditional reinforcement with the benefit from all advantages of longitudinal voids mentioned previously.

- The difference in ultimate strength capacity between specimens reinforced with traditional rebars and with those reinforced with steel pipes may be related to the difference in elastic properties between the used reinforcements.

- The steel pipe reinforce beam stiffness after cracking stage is larger than the stiffness of equivalent beams reinforced with rebars because of the large stiffness of steel pipes with respect to traditional rebars as well as the bond strength along the steel pipes is larger than the bond strength along the traditional steel rebars which have a smaller surface area.

- Large size openings provided by large size steel pipes need more confinement by either increasing surrounding concrete or increasing of stirrups at the ends.

\section{References}

Al-Khekany, A.M., Al-Yassri, L.S. \& Abbas, H.S. (2018). An experimental investigation of hollow composite column reinforced by multi-skin square and round steel tube. International Journal of Civil Engineering and Technology, 9(11), 784-793.

Al-Yassri, L.S., Al-Khekany, A.M. \& Abbas, H.S. (2018). Experimental study of replacement the tension reinforcing bars in concrete beams by steel pipes. International Journal of Engineering and Technology, 7(4.20), 229-234.

American Concrete Institute [ACI] (2014). Building Code Requirements for Structural Concrete and Commentary (ACI 318-14). 
Farmington Hills (MI): American Concrete Institute.

Amin, H.M., Agarwal, V.C. \& Aziz, O.Q. (2013). Effect of opening size and location on the shear strength behavior of RC deep beams without web reinforcement. International Journal of Innovative Technology and Exploring Engineering, 3(7), 28-30.

Arya, C. (2009). Eurocode 2: Design of concrete structures. In Design of Structural Elements. (pp. 314-374). New York: Taylor \& Francis.

Ashour, A.F. \& Rishi, G. (2000). Tests of reinforced concrete continuous deep beams with web openings. Structural Journal, 97(3), 418-426.

Campione, G. \& Minafò, G. (2012). Behaviour of concrete deep beams with openings and low shear span-to-depth ratio. Engineering Structures, 41, 294-306.

Canadian Standards Association [CSA] (2004). Design of concrete structures (CSA A23.3-04). Mississauga, Ontario: Canadian Standards Association.

Central Organization for Standardization and Quality Control [COSQC] (1984a). Portland cement (IQS 5/1984). Baghdad: Central Organization for Standardization and Quality Control.

Central Organization for Standardization and Quality Control [COSQC] (1984b). Aggregates from natural sources for concrete and building construction (IQS 45/1984). Baghdad: Central Organization for Standardization and Quality Control.

Hasnat, A. \& Akhtanizzamam, A.A. (1987). Beams with small rectangular opening under torsion, bending, and shear. Journal of Structural Engineering, 113(10), 2253-2270.

Herrera, L., Anacleto-Lupianez, S. \& Lemnitzer, A. (2017). Experimental performance of RC moment frame beams with rectangular openings. Engineering Structures, 152, 149-167.

Makki, R.F., Jassem, A.T. \& Jassem, H.A.A.L. (2018). Non-linear analysis of Reactive Powder Concrete (RPC) deep beams with openings strengthened by CFRP. Al-Qadisiyah Journal for Engineering Sciences, 11(2), 176-196.

Mansur, M.A., Tan, K.H. \& Lee, S.L. (1984). Collapse loads of $\mathrm{R} / \mathrm{C}$ beams with large openings. Journal of Structural Engineering, 110(11), 2602-2618.
Prentzas, E. (1968). Behavior and reinforcement of concrete beams with large rectangular apertures. Sheffield: University of Sheffield.

Sethunarayanan, R. (1960). Ultimate strength of pre-tensioned I-beams in combined bending and shear. Magazine of Concrete Research, 12(35), 83-90.

Somes, N.F. \& Corley, W.G. (1974). Circular openings in webs of continuous beams. Special Publication, 42, 359-398.

Yang, K.H., Eun, H.C. \& Chung, H.S. (2006). The influence of web openings on the structural behavior of reinforced high-strength concrete deep beams. Engineering Structures, 28(13), 1825-1834.

\section{Summary}

Experimental investigations on concrete beams reinforced with equivalent service steel pipe. Different techniques were employed for the passage of different utilities through structural elements. The reduction of the overall building weight was the main concern that needs to be achieved, especially for a multistory building. It can be done with the eliminating of a suspended ceiling with a portion of the beam's weight by taking the advantages of the hollow sections. In this study, an equivalent reinforcement to the traditional ribbed reinforcement was employed to fabricate a reinforced concrete (RC) beam with a hollow section along the length of the beam. A steel pipe was used based on the equivalent moment from section analysis. Two diameters were selected of steel pipes as an equivalent to the commercial reinforcement. A total of four RC beams were cast and tested, two of them with traditional reinforcement and the other with steel pipe reinforcement. The comparison showed a promising result in terms of ductility, cracking pattern, ultimate strength, and mode of failure compared to the reference beam. The peak loads for the specimens with steel pipe were $160.6 \mathrm{kN}$ and $184 \mathrm{kN}$, while they were $192 \mathrm{kN}$ and $203.5 \mathrm{kN}$ for the beams with traditional reinforcement. 


\author{
Authors' address: \\ Labeeb S. Al-Yassri \\ (https://orcid.org/0000-0002-2664-1506) \\ Munaf A. Al-Ramahee \\ (https://orcid.org/0000-0002-1922-9871) \\ Alaa M. Al-Khekani \\ (https://orcid.org/0000-0001-8474-6798) \\ University of Al-Qadisiyah \\ College of Engineering \\ Civil Engineering Department \\ e-mail: labeeb.husein@qu.edu.iq \\ Munaf.alramahee@qu.edu.iq \\ alaa.alkhekany@qu.edu.iq
}

